\title{
Integrating highly qualified migrants: allowing a personal narrative to set future research directions
}

\author{
Aida Hajro \\ Brunel Business School, \\ Brunel University London, \\ Eastern Gateway Building, \\ Uxbridge, UB8 3PH, \\ London, UK \\ Email: aida.hajro@brunel.ac.uk
}

\begin{abstract}
Using a unique case history of a highly qualified migrant family pushed from its country of origin due to war, I elucidate the emotional, cultural, societal and situation-specific challenges that its members faced in their new country of destination. I then link their stories to the current literature in the field of migration studies and formulate several avenues for future research. By allowing narrative theory to guide the field, I make a contribution to the current discourse and formulate questions that truly matter.
\end{abstract}

Keywords: acculturation processes; challenges; highly qualified migrants; integration outcomes.

Reference to this paper should be made as follows: Hajro, A. (2017) 'Integrating highly qualified migrants: allowing a personal narrative to set future research directions', European J. Cross-Cultural Competence and Management, Vol. 4, Nos. 3/4, pp.192-200.

Biographical note: Aida Hajro is a Senior Lecturer in International Business at Brunel University London. She received her PhD in Business Studies from the Vienna University of Economics and Business. She studies how different aspects of organisational context influence collective cognitive processes in teams, how team learning processes drive organisational change, and coping strategies and acculturation processes of highly qualified migrants. Her research has been published in journals such as Academy of Management Journal, International Journal of Human Resource Management, Schmalenbach Business Review, and International Journal of Cross-cultural Management.

\section{Introduction}

With the refugees fleeing from the conflict-torn countries in the Middle East and North Africa (MENA) region, Europe is currently facing a historical moment with one of the largest migration movements in history. The resulting fears about being flooded by individuals who might impose a burden on taxpayers, local values and cultures have made it difficult to set out the facts and the evidence needed to inform a balanced public debate. The consequences are fuelling populism and mistrust that have deteriorated the diversity climates of many countries (OECD, 2016). This in turn has not only negatively 
impacted asylum applicants but is also changing attitudes towards those migrants who hold a university degree and have moved on a permanent basis to live and work in countries other than their own (Cerdin et al., 2014; Kühlmann et al., 2016a).

Although the qualification capabilities and international understandings that these highly qualified migrants bring to their employers are critical to the future of many European companies (Cerdin et al., 2014), their integration into the host-country society is hampered by numerous challenges (Kühlmann et al., 2016a). Yet if Europe wants to remain competitive in the 'global competition for talent', it needs to retain and integrate highly qualified labour. While there are studies and reports that provide indicators regarding challenges for migrants to European countries in general, the analysis of such barriers for the specific group of highly qualified third-country nationals is constrained by limited literature on this topic (Bittman, 2013; Kühlmann et al., 2016b; Hajro and Zilinskaite, 2016). Hence, we do not know what the challenges that highly qualified migrants face in light of growing populism and mistrust in many European countries are. What are the psychological processes and behavioural strategies that highly qualified migrants use to overcome these challenges? How can knowledge about their acculturation patterns help us improve their integration? And what can we do to help them set adequate intentional actions in their new country of destination? These questions represent pieces of a puzzle that still remains to be solved.

Using the narrative approach, I describe how my parents and I made sense of events we faced as migrants pushed from our country of origin due to war, how we decided what actions to take in order to integrate into our new society and what role host-country nationals, who were willing to guide and support us, played in fostering our positive acculturation outcomes. I then link my own experience to the current literature in this domain and formulate several avenues for future research. By asking questions about the narrative that guided my life and joining in the conversations of leading academics in this field, I aim to contribute to the current discourse. In addition, I hope to inspire and motivate other scholars to embark on a journey of discovery, a journey that cannot wait.

In the sections that follow, I first describe the personal circumstances surrounding the formative years of my life that formed my personality and later triggered my desire to study the patterns that result in different acculturation dynamics of highly qualified migrants. Based on my personal narrative, I then formulate several research questions.

\section{My personal life story as migrant}

I will start with my early years as a child of expatriate parents and will then summarise the critical experiences I made as a child of highly qualified migrants. Making this distinction is important in order to highlight the distinct challenges people face in these two different contexts.

I was born in Sarajevo, the capital and largest city of Bosnia and Herzegovina. At the age of 1 year, I moved with my family to Mexico City where my father worked as expatriate of a major Bosnian engineering and energy company for 5 years. I experienced Mexico as a wonderful country characterised by rich ethnic diversity, a country where I felt respected, appreciated and admired for being a child of Bosnian parents. In the early 1980 s, Mexico City was still not as culturally diverse as it is now. Hence, we represented an 'exotic minority group' that was perceived very positively. In the presence of positive attitudes towards us as 'Bosnians or Europeans' and according to my parents' memories, 
we did not experience negative critical incidents. This helped us to maintain a strong sense of who we were and at the same time learn from the Mexican culture.

In 1986, we moved back to Sarajevo, a city that is often called Jerusalem of Europe due to its traditional religious diversity, with adherents of Islam, Orthodoxy, Catholicism and Judaism. Both my parents were very open-minded and tolerant, and I grew up without really knowing to which religious group I belonged until the days Bosnia declared its independence from former Yugoslavia and concentration camps returned to Europe for the first time since the Second World War. The beautiful city of Sarajevo was suddenly besieged, its food and electricity supplies cut-off and its civilian population relentlessly bombarded. This is the year I learnt that I had an Arabic name and as consequence was classified as Muslim. My presence on the lands of Bosnia suddenly became undesirable. I will never forget the first official day of war. It was a Sunday. My parents and brother were still sleeping as I woke up to take my dog for a walk. To my surprise, the streets of Sarajevo were completely empty that morning. At the age of 12 years, I could not envisage what was going on. Hence, I assumed that everybody was still sleeping. After $20 \mathrm{~min}$ of walk, I reached the riverbank of Miljacka where I used to meet my friends every weekend. Yet nobody was there. The city felt so silent and calm. I sat down on a park bench and waited to see what will happen while my dog was exploring the surroundings. Suddenly, I heard the voice of a friend. She was running towards me, screaming at me: "Don't you know? They have barricaded the area where you live. There are armed soldiers everywhere. You should run home! Now!" I did not wait. I ran as fast as I could. It was not the first time that the city was occupied by armed forces, but the first time I was in the streets alone and unprotected as it happened. My dog started pulling on the leash. Yet, I did not try to stop him. Instead, I released the leash hoping that he would run after me. It was pure panic and fear that made me do this. As I finally reached my neighbourhood, I felt exhausted. I had to stop and try to catch my breath. I was happy that my dog was still there. Yet, then suddenly I heard a big German shepherd burking from the balcony of a nearby building. I knew this dog but I had never seen him in this fierce condition before. His legs were apart and chest thrown out making him look bigger. He was showing his front teeth as if he wanted to warn me of possible danger. Then, suddenly I heard gunshots. I was terrified. I ran in disbelief that somebody was shooting at me, a 12-year-old girl. I will never forget the moment I finally reached our apartment. My mother hugged me tight with tears in her eyes, not wanting to release me ever again. I was back home alive.

We were lucky that we escaped from the war in Sarajevo that same month. Many of my friends and relatives remained trapped inside the city for almost 4 years. The war ended in 1995. After more than 100,000 deaths and a massacre in which 8,000 unarmed Muslim men were murdered in the town of Srebrenica, Nato finally intervened. We left Sarajevo in April 1992. Our journey took us back to Mexico, where we initially intended to stay. Yet, finding employment turned out to be trickier than my father had expected. That same year in August he received an offer from a major Austrian corporation. He accepted the 100-day consultancy contract (which later turned into a permanent contract) and we moved to Vienna. Soon after we arrived, my father contacted his good old friend Karl Korn. I have never met this gentleman in person, but I know that he guided and supported my father. They would regularly meet in the city. Karl would take my father to places accessible only to the 'Viennese' society. He would advise him how to interact with Austrians and more importantly teach him how to gain their trust. During one of their meetings, Karl told my father, "Look, Austrian people will remain formal and 
reserved towards you as long as you don't establish a personal relationship with them. Now that you have received a permanent contract you should invite your work colleagues to celebrate this milestone with you. Organise a get together, serve some traditional Bosnian food, tell them something about your country and culture, and show them who you are not only as technical expert and professional but as a person." My father took Karl's advice seriously. The event helped him to get to know the people including members of the senior management with whom he was interacting on a more personal level. In Austria, a society where relationships are often perceived to be more important than universal values and norms, this was critical. The level of trust my father achieved with his colleagues through this event and his follow-up interactions with them became contingent upon their perceptions of my father's ability, honesty and integrity as person and leader. He remains infinitively grateful to Karl for this advice. Interestingly, every time my father asked him, "Why are you helping us?," Karl would tell him, "I had the same destiny, so I know what you are going through." For years, we believed that Karl was Austrian who resisted Hitler and Nazi Germany. Yet 8 years later, when Karl died and my father took us to his funeral, we learned that he was a Jew who was forced to leave Austria during the Second World War.

The first year of my life in Vienna was very difficult. Although we lived in the 19th district, one of Vienna's poshest living areas, where I was officially entitled to go to any public school, all my applications got rejected based on the argument that I could not speak German. Luckily, the director of a public school in the 22nd district, who was a close friend of a colleague of my father, agreed to provide a place for me. From that moment on I had to commute every day for $2 \mathrm{~h}$. Yet, I was happy that I could go to school. Since I could not speak German, I was asked to sit in the last row. I must admit that at the beginning I felt very isolated, lonely and rejected. I could not communicate with the children since I could not speak their language. Although we were all the same age, I felt that I was far more mature. The life experiences I had to go through had forced me to grow up overnight. At the age of 12 years, I no longer felt like a child.

Two months later, an incident happened that suddenly changed the way my teachers and classmates perceived me. We had our first mathematics' exam. Since I could not understand German, nobody expected me to pass this one. Yet then to the surprise of all including myself, I got the highest score in the class. That same day I was asked to move to the first row. From that moment on, I had a special standing in the school. The news about the 'gifted child' in class $2 \mathrm{e}$ soon also attracted the attention of other teachers. Among them was Hilda, a very warm, accessible and caring pedagogue. She knew that I was going through a very difficult time. Hence, during the breaks, she would often come to see me and ask how I was doing. This meant a lot to me. The fact that there was somebody at school who truly cared about me and who was attentive to the socialemotional needs that $I$ had at that time became a pillar of confidence for me. By giving me a sense of security and belonging, she indirectly shaped my self-esteem. Having her as a source of stability and guidance reassured and encouraged me to participate in group activities, to communicate with children despite my weak German language skills, and to maintain my curiosity and willingness to learn from them.

Nevertheless, the first year of life in Vienna remains the toughest year of my entire life. I was at school from 8 am to $2 \mathrm{pm}$ every day. From $4 \mathrm{pm}$ to $8 \mathrm{pm}$, I would then attend German classes that were organised by the Goethe-Institute. Today, I often ask myself how I was able to cope with such a high workload at such a young age. What motivated me were people like Hilda, who were willing and able to emotionally support 
me and my parents. I saw the pain and fear my parents felt. My father was 47 years old when he lost everything he had built up in 25 years and moved to a German-speaking country without the knowledge of the local language with two young children and his wife, leaving all his relatives and friends in the encircled Sarajevo that today stands for the longest siege of a capital city in the history of modern warfare. I felt that the only way to help my parents was to work hard, learn German and prove that I could pass all my school exams. Knowing that my parents had to start from scratch again, with no savings and an uncertain future since my father's contracts were time limited at the beginning and my mother had difficulties finding a job as lawyer in Austria, I decided to help them by being modest and trying to save money. But how could I save money? On the first day of school, I learnt that we could chose to eat full lunch or have only soup. Having full lunch was more expensive, and so I chose to eat only the soup without the main course for the whole year in hope that this would relieve my parents from financial pressures. In reality, this was not the case since school meals were partly government funded and offered at a very low price but in my childish imagination I felt that I was doing something good. I never told my parents about this. Today, when I look at the pictures of the refugees arriving in Europe from war-torn countries in the Middle-East, I ask myself, "Do their children feel the same pain, uncertainty, and fear that I felt as a child, or is their loss even greater than mine?" After all, I would say that I was very lucky.

It took me 1 year to learn German but much longer to get integrated into the Austrian society. In Austria, I was not appreciated or admired for being a child of Bosnian parents. I was perceived as a girl from a poor, conflict-torn country, a country known in Western Europe for its refugees and low-skilled migrants. It was a painful experience. Yet although many Austrian people held negative attitudes towards Bosnians and were not very inclusive in their orientation towards cultural diversity at that time, my family did not choose to assimilate, nor separate or marginalise. We knew that the only way for us to succeed in our new 'home country' was to internalise Austrian values and norms of behaviour but at the same time to maintain our original culture. My father would often tell me, "If you don't appreciate who you are, how can you expect the others to value you?" Today, I am proud to say that I am from Sarajevo. I am also very proud of the facts that I had lived in Mexico, studied in Austria and the United States, and that I work in London. These cross-cultural experiences have made me who I am and triggered my desire to study issues related to multicultural teams, cross-cultural management and acculturation patterns of highly qualified migrants. Frieda Kahlo, the famous Mexican artist, once said, "I paint myself because ... I am the subject I know best" I believe that many of us do the same: we research topics that are closely related to our personal life experiences.

\section{Future research avenues: making meaningful contributions to academia and society}

Based on previous research and my personal life experience, I will now summarise several avenues for future research.

\footnotetext{
"The more clearly we understand the roots of our identity and humanity, the more able we will be to use our strengths and core values to achieve the vision we have for ourselves and the world around us."(Adler, 2008: 13)
} 
At last year's Academy of Management meeting, I attended an interesting talk on multicultural identities. One of the important issues that came up was whether a strong national cultural identity was a hindrance to the creation of a multicultural mind-set. One of the participants asked the following question, "Can we organize more than one cultural identity by internalizing different associated cultural schemas, even if we have a very strong core national cultural identity?" Although the session was attended by several internationally well-known scholars, we did not manage to come to a conclusion. Opinions remained divided. Therefore, I believe that this represents an interesting question for future research. I often ask myself if my father who taught me to appreciate and value my Bosnian heritage, indirectly helped me to integrate into the Austrian society. By teaching me the very essence of who I am, did he give me the self-confidence that I needed to maintain my original values and at the same time learn from the Austrian culture?

While behaviours of those who love me the most certainly have had a strong influence on my personality development, I also ask myself what characteristics or traits underlined my personality back in 1992, and how and why this supported my integration into the Austrian society. How do, for instance, the Big Five personality characteristics (extroversion, agreeableness, conscientiousness, emotional stability and openness or intellect) link to acculturation outcomes of highly qualified migrants? While there is some work on personality characteristics as predictors of expatriate behaviour (Caligiuri, 2000), we do not know how these characteristics are linked to behavioural strategies and psychological processes of highly qualified migrants.

Furthermore, existing research has mainly examined the diverse coping strategies used by expatriate managers in response to the problems encountered while on international assignments (Stahl and Caligiuri, 2005). Yet, it remains unknown how highly qualified migrants make sense of their experiences and what behavioural strategies they use in order to adjust to their new life situations. In contrast to expatriates, who are transferred by their organisations on temporary contracts (Reiche, 2011), highly qualified migrants move on their own initiative, with the intention to settle permanently in a country other than their place of origin (Cerdin et al., 2014). In addition, many of them come from developing countries, and for that reason are less advantaged in terms of their ethnic origins than expatriates (Al Ariss and Crowley-Henry, 2013). How highly qualified migrants cope with the challenges they encounter in the new country of destination (e.g. stereotyped image of migrants, discrimination, cross-cultural differences, etc.) and what coping strategies they develop as a result represents an interesting avenue for future research. While studies in the field of expatriation have shown that problemfocused coping strategies (e.g. learning more about the host country) are more useful in improving adjustment to host culture compared to emotion-focused coping strategies (e.g. expatriate who withdraws into the expatriate enclave to regulate emotions that result from the stress) (Feldman and Thomas, 1992; Tung, 1998; Stahl and Caligiuri, 2005), I am wondering if the same applies to migrants. If you take my experience as a child of highly qualified migrants as example (and I know that my parents faced similar challenges), the only way for me to integrate into the Austrian society was by learning at a very early stage in my life how to cope with discrimination (e.g. stereotyped image of Bosnian refugees), feeling of being rejected (e.g. not provided a place at school based on the argument that I could not speak German), undervalued (e.g. asked to sit in the last row) and misunderstood (e.g. many people did not know what it felt like to come from a worntorn country). In order to cope with these life experiences, I had to develop effective 
emotional strategies, in addition to problem-focused coping strategies. In this process, I learnt two important things. First, having courage to see reality as it was, was very important. Second, it was crucial not to give up finding possibilities even when the situations we had to go through as family seemed hopeless. In order to achieve this, I had to regulate and adjust the emotions that were triggered by my life circumstances (e.g. fear and hopelessness) in a way that helped me to ultimately reach my goals (e.g. by developing confidence and becoming hopeful).

As already mentioned above, my parents and I were not alone on our journey. 'Friends' or 'mentors' who were willing to guide and support us in our new country of destination, fostered our integration by providing us with emotional support, increasing our cultural awareness, encouraging us to remain persistent and pointing at possibilities even when the present appeared extremely bleak. My father's Jewish friend Karl, who helped him to remain hopeful during the most difficult time of his life, did not only create a lasting impact on my father, but also on me. His act of humanity taught me that people from all religions and nationalities can act with integrity and that there is no such a thing as a black-and-white-world. Furthermore, Karl indirectly facilitated the cross-cultural interactions of my father with his colleagues by advising him how to interpret behaviours and reactions of Austrians under certain circumstances, what behavioural patterns to expect from them in business and how to create trustworthy relationships with them. He referred to the different kinds of perceiving, thinking, judging and acting that in the Austrian culture were considered as normal, self-evident, typical and obligatory by the majority of its members (Thomas, 1993; Fink et al., 2005). By deliberately passing his tacit cultural knowledge and wisdom on to my father, Karl helped him to get better integrated into his new country. Interesting work on mentoring partnerships has been conducted in Canada (Zikic, 2016); however, there is neither research on building successful exchange relationships between mentors and mentees in other cultural contexts, nor are there studies that explore how host-country nationals can foster positive acculturation outcomes of highly qualified migrants. For instance, we do not know how cultural standards defined as socially shared and accepted norms (Thomas, 1996; Landis et al., 2004) can be passed on to migrants through formal and informal mentors. How can mentors increase migrants' cultural awareness? Finally, what personality characteristics do such mentors need to have in order to set adequate intentional actions that will foster the integration of these individuals, and what role does emotional support play in this relationship?

Today, many of the migrant refugees who are seeking asylum in Europe have fled countries where major conflicts have taken place or where serious human rights abuses occur. They have experienced trauma, abandonment and treacherous flights to safety. We cannot expect that they will integrate into our societies immediately unless we provide them with the adequate socio-emotional support and help them to focus on what they can change to make things better in their life. Integration is a lengthy process that depends on many external factors. Coming from a war-affected country was a traumatic experience in itself for me. Integrating into a new society, a society that was culturally distinct from the one I knew, represented an additional - no less important - challenge. Without the emotional support of my parents and individuals like my teacher Hilda, my journey would have been far more difficult.

Another hidden aspect of migration in the literature is the under-researched role that societal values play in constraining or promoting migrants' ability to cope with the integration challenges in the destination country. One could argue that in particularist 
societies where less attention is given to abstract societal rules and where friendship has special obligations, and personal relationships and connections often times come first, highly qualified migrants might encounter more challenges as 'outsiders' or 'newcomers' than in universalistic countries, where the same rules apply to all (Trompenaars and Hampden-Turner, 1997). In my case, I was extremely lucky that my father's colleague agreed to introduce me to his friend, who at that time was the director of the public school in the 22 nd district. Thanks to this acquaintance, I was able to continue with my education.

In this short contribution, I have presented the narrative that has and will continue guiding my life as a scholar. One could argue that it lacks 'objectivity' and as a result does not comply with scientific norms. Yet, what I believe it certainly does, it addresses questions that really matter not only to me personally but also to the world we are currently living in (Adler and Hansen, 2012). I hope that my example will motivate junior scholars to reflect on what forms the basis for their own research and encourage them to ask questions that really matter, questions that will help us to address some of the most pressing challenges of our time.

\section{References}

Adler, J.N. (2008) 'I am my mother's daughter: early developmental influences on leadership', European Journal of International Management, Vol. 2, No. 1, pp.6-21.

Adler, J.N. and Hansen, H. (2012) 'Daring to care: scholarship that supports the courage of our convinction', Journal of Management Inquiry, Vol. 21, No. 2, pp.128-139.

Al Ariss, A. and Crowley-Henry, M. (2013) 'Self-initiated expatriation and migration in the management literature: present theorizations and future research directions', Career Development International, Vol. 18, pp.78-96.

Bittman, T. (2013) Highly Qualified and Qualified Immigration of Third-Country Nationals: Legislation, Measures and Statistics in Austria, International Organization for Migration, Vienna. Available at: http://ec.europa.eu/dgs/home-affairs/what-we-do/networks/european migration_network/reports/docs/emn-studies/01a.austria_highly_qualified_study_final_en_ version.p $\overline{\mathrm{df}}$

Caligiuri, P.M. (2000) 'The big five personality characteristics as predictors of expatriate's desire to terminate the assignment and supervisor-rated performance', Personnel Psychology, Vol. 53, No. 1, pp.67-88.

Cerdin, J-L., Diné, M.A. and Brewster, C. (2014) 'Qualified immigrants' success: exploring the motivation to migrate and to integrate', Journal of International Business Studies, Vol. 45, No. 2, pp.151-168.

Feldman, D.C. and Thomas, D.C. (1992) 'Career management issues facing expatriates', Journal of International Business Studies, Vol. 23, pp.271-294.

Fink, G., Koelling, M. and Neyer, A-K. (2005) The Cultural Standards Method, European Working Paper, Number 62.

Hajro, A. and Zilinskaite, M. (2016) 'Organizational climate for inclusion and the resulting challenges and coping strategies of highly-qualified migrants', Paper presented at the Conf. Eur. Int. Bus. Acad., 2-4 December, Vienna.

Kühlmann, T., Heinz, R., Stahl, G. and Hajro, A. (2016a) 'Managing cultural diversity in European companies: implications for professional migrants from Non-EU countries and their employers', Paper presented at the Acad. Manage. Meet., 4-9 August, Anaheim. 
Kühlmann, T., Stahl, G., Heinz, R., Hajro, A. and Vodosek, M. (2016b) 'Integrating highly qualified immigrants (HQIs) into European small and medium-sized organizations: the roles of individual effort, organizational support and social support', Paper presented at the Conf. Eur. Int. Bus. Acad., 2-4 December, Vienna.

Landis, d., Bennett, J.M. and Bennett, M.J. (2004) Handbook of Intercultural Training, Sage Publications, Thousand Oaks, CA.

OECD (2016) International Migration Outlook 2016, OECD Publishing, Paris.

Reiche, B.S. (2011) 'Knowledge transfer in multinationals: the role of inpatriates' boundary spanning', Human Resource Management, Vol. 50, No. 3, pp.365-389.

Stahl, G. and Caligiuri, P. (2005) 'The effectiveness of expatriate coping strategies: the moderating role of cultural distance, position level, and time on the international assignment', Journal of Applied Psychology, Vol. 90, No. 4, pp.603-615.

Thomas, A. (1993) Kulturvergleichende Psychologie: Eine Einführung, Hogrefe Verlag für Psychologie, Göttingen/Bern/Toronto/Seattle.

Thomas, A. (1996) 'Training interkultureller Kompetenz', in: Bergemann, N. and Andreas L.J. (Eds.): Sourisseaux: Interkulturelles Management, Springer, Berlin, Germany, pp.237-272.

Trompenaars, F. and Hampden-Turner, C. (1997) Riding the Waves of Culture: Understanding Cultural Diversity in Business, 2nd ed., Nicholas Breazley, London.

Tung, R.L. (1998) 'American expatriates abroad: From neophytes to cosmopolitans', Journal of World Business, Vol. 33, pp.125-144.

Zikic, J. (2016) 'Professional migrants at the institutional periphery: the strength of professional identity \& social capital as critical resources against brain waste', Paper presented at the Acad. Manage. Meet., 4-9 August, Anaheim. 